\title{
JUNGHANS, Helmar, Die sächsischen Kurfürsten während des Religionsfriedens von 1555 bis 1618
}

\section{Naïma Ghermani}

\section{OpenEdition}

\section{Journals}

Édition électronique

URL : http://journals.openedition.org/ifha/1833

DOI : $10.4000 /$ ifha. 1833

ISSN : 2198-8943

Éditeur

IFRA - Institut franco-allemand (sciences historiques et sociales)

Référence électronique

Naïma Ghermani, « JUNGHANS, Helmar, Die sächsischen Kurfürsten während des Religionsfriedens von 1555 bis 1618 », Revue de l'IFHA [En ligne], Date de recension, mis en ligne le 01 janvier 2009, consulté le 22 septembre 2020. URL : http://journals.openedition.org/ifha/1833 ; DOI : https://doi.org/10.4000/ ifha. 1833

Ce document a été généré automatiquement le 22 septembre 2020.

(C)IFHA 


\title{
JUNGHANS, Helmar, Die sächsischen Kurfürsten während des Religionsfriedens von 1555 bis 1618
}

\author{
Naïma Ghermani
}

1 Cet ouvrage collectif à la mémoire du professeur Günther Wartenberg, philologue, professeur de théologie à Leipzig mais aussi éditeur de la correspondance politique du duc puis de l'électeur Maurice de Saxe, prend pour point de départ l'intérêt de celui-ci pour l'histoire politique et religieuse de la Saxe au XVIe s. à laquelle il avait consacré sa thèse d'habilitation, pour proposer un riche panorama sur les relations politiques et diplomatiques de ce territoire-clé du Saint-Empire. Le fonds d'archives conservé aux archives principales d'État de Dresde des princes Auguste de Saxe, Christian Ier, Christian II et Johann-Georg que présente G. MARTIN en vue d'une future édition, offre en effet un terrain de recherche immense. À travers de très nombreuses contributions qui ont le mérite de remettre à jour une partie de la bibliographie sur la question, ce recueil étudie tour à tour les relations diplomatiques de la Saxe électorale avec le Danemark (J.E. OLSEN), la Hesse (M. RUDERSDORF), la Saxe ernestine à qui Maurice avait soufflé le titre électoral après la défaite de son cousin et rival à la bataille de Mühlberg en 1547 (V. LEPPIN). J. BRUNING propose quant à lui une analyse plus vaste sur la politique de la Saxe électorale sur la scène de l'Empire avant la guerre de Trente Ans.

2 Un second volet se penche sur des aspects plus précis de l'histoire territoriale des électeurs de Saxe pendant cette période de pacification religieuse dans ses aspects ecclésiastiques, culturels et politiques. La mort de Maurice de Saxe dont la perception est étudiée par C. WINTER, sur le champ de bataille, lui permet par cette fin sacrificielle de redorer son image fortement ternie par sa trahison d'avant 1547. La fin de son règne ouvre ainsi une ère fastueuse pour la branche albertine de Saxe : à l'instar des grands territoires d'Empire comme la Bavière ou le Palatinat, la Saxe électorale connaît pendant ces premiers temps de la confessionnalisation une phase de «territorialisation » qui se traduit par une ambitieuse politique universitaire (A. GÖßNER), par une 
extension du domaine de compétence de l'État notamment dans le domaine religieux et scolaire (H. JUNGHANS et A.-K. KUPKE) mais aussi sur un plan plus symbolique, par des projets bâtisseurs destinés à leurs propres résidences (S. DELANG) ou à de nombreux édifices religieux (H. JADATZ). Cette intervention du temporel dans le domaine religieux est marquée également par l'influence décisive de l'Électorat de Saxe dans la mise en place d'une orthodoxie luthérienne qui mettait fin à près de quarante ans de luttes intra-confessionnelles (C. PETERS). W. SOMMER s'interroge d'ailleurs à juste titre sur l'influence des prédicateurs de cour dans cette importante politique confessionnelle, dans un contexte d'échec relatif de la paix d'Augsbourg (G. WARTENBERG). Ce renforcement étatique favorisé par la Paix de 1555 est aussi l'objet d'une importante réflexion dans l'entourage du prince, notamment auprès d'un des conseillers d'Auguste de Saxe, Melchior von Osse dans son Testament politique de 1555/1556 qui permet au genre antique du miroir de prince de s'ouvrir à des problématiques nouvelles, notamment celle de la politique économique (R. GROß).

Enfin, la contribution de K. KELLER consacrée aux princesses-électrices de Saxe vient, contrairement aux articles précédents, moins faire un bilan des recherches que combler un manque important dans l'histoire du genre, et plus précisément des femmes des électeurs, en s'arrêtant sur deux cas précis : la princesse Anna, première femme d'Auguste de Saxe, qui joua un rôle politique important ; et Sophie, épouse de Christian Ier de Saxe et veuve à 23 ans. Ce recueil offre donc un tour d'horizon complet de l'histoire de ce territoire pendant la période cruciale de la coexistence pacifique dans l'Empire.

4 Naïma GHERMANI (Université de Grenoble II) 